\title{
Desktop Map Design: Some Odysseys of Form and Flow
}

Making maps on today's desktop platforms can be something of an odyssey that often obliges the designer to traverse minefields of nonintegrated software. This article details the workflows for nine maps produced with desktop computer software. Each workflow falls across a row; each row references a captioned map that was a tangible outcome of the author's implementation of desktop cartography using image processing and other software tools. A need for early articulation of appropriate verbal goals to guide the power and charm of map design software is discussed.

Few people dispute that creating maps "on the desktop" (i.e. cartography using microcomputers) has considerably altered both map genesis and map production. My goal here is to usher a reader through a few specific desktop mapmaking processes undertaken during a half-year sabbatical. Creation and production processes afforded by new technology are often thought to be faster and more flexible than traditional methods and may result in workflows worth documenting and sharing. Of some interest is the way these flows express and interact with aesthetic zeitgeists past and in emergence today.

Making maps today that effectively communicate probably demands more than any single software application can alone provide. Grant Thrall speculates why (Thrall 1992):

At the first stage of the mass-market microcomputer revolution, a fantasy existed that integrated software could successfully combine into one program several interconnected modules whose functionality could otherwise only be obtained in stand-alone products.

He observed that it is rare that a module of an integrated software program can compete in features with the very best stand-alone applications. He claimed that such an integrated program lately "has been relegated to novice computer users or undemanding 'executive' computer users." Though Professor Thrall was referring in particular to "wholly self-contained [GIS] integrated software," his lattermost assertion seems generally true across the microcomputer worlds of Macintosh, and Microsoft DOS and Windows. But squarely within map design and pre-press production there does exist integrated software that seems to actually work; it is found on workstations offered by proprietary vendors (example: Intergraph) who supply "turnkey systems" (example: MGE). Common wisdom suggests one might best take a balanced view of the value of such integrated systems. For example, if modules of turnkey systems have a uniformly designed interface one may argue that as a clear benefit to desktop users. On the other hand, cost and steep learning curves are usually present as liabilities.

Until something quite revolutionary happens in the world of microcomputer software, a key to effective map design and production may be, on the one hand, to grin and bear the "disintegration" of our times, while on the other to continue identifying relevant individual software tools and intelligently interconnecting them, in the right order with the best conceptual and communication goals in mind.

\section{Kevin Byrne}

Kevin Byrne is an Associate Professor at the Minneapolis College of Art and Design and consults in the area of urban information design. Address: 1827 Franklin Avenue S.E., Minneapolis, MN 55414.

SOFTWARE TOOLS FOR MAP DESIGN: CAN WE TOLERATE TODAY'S DISINTEGRATION? 
TOOLS IN ACTION: TRACKING MAP WORKFLOWS ACROSS A MATRIX

A reader's strategy for tracing the software workflows below might be to 1) track the lower case letters in a chosen sequence across its corresponding row, and 2) refer to the article's captioned figures which appear on pages that follow.
The smooth passing of data and imagery between stand-alone software tools has probably thus become the desktop map design "challenge of the 90 s." I sought to better understand this "disintegrated" new world of desktop cartography by undertaking the design and production of six "demonstration" maps. The matrix shown below is a detailed tabular expression that focuses on the presentation of workflows completed for these maps. Additional descriptions of anecdotal and technical interest accompany specific workflow depictions. The matrix also features three minor experiments in "illustrative" image processing, each also shown as a workflow sequence. demo map titles...

Divorce transect

Ghost dance

City neighborhood

Horse diffusion

Frontiers travel

Farm relief

a few experiments... U. S. divorce map 'texturized'

Neighborhood map 'texturized'

Raisz patterns

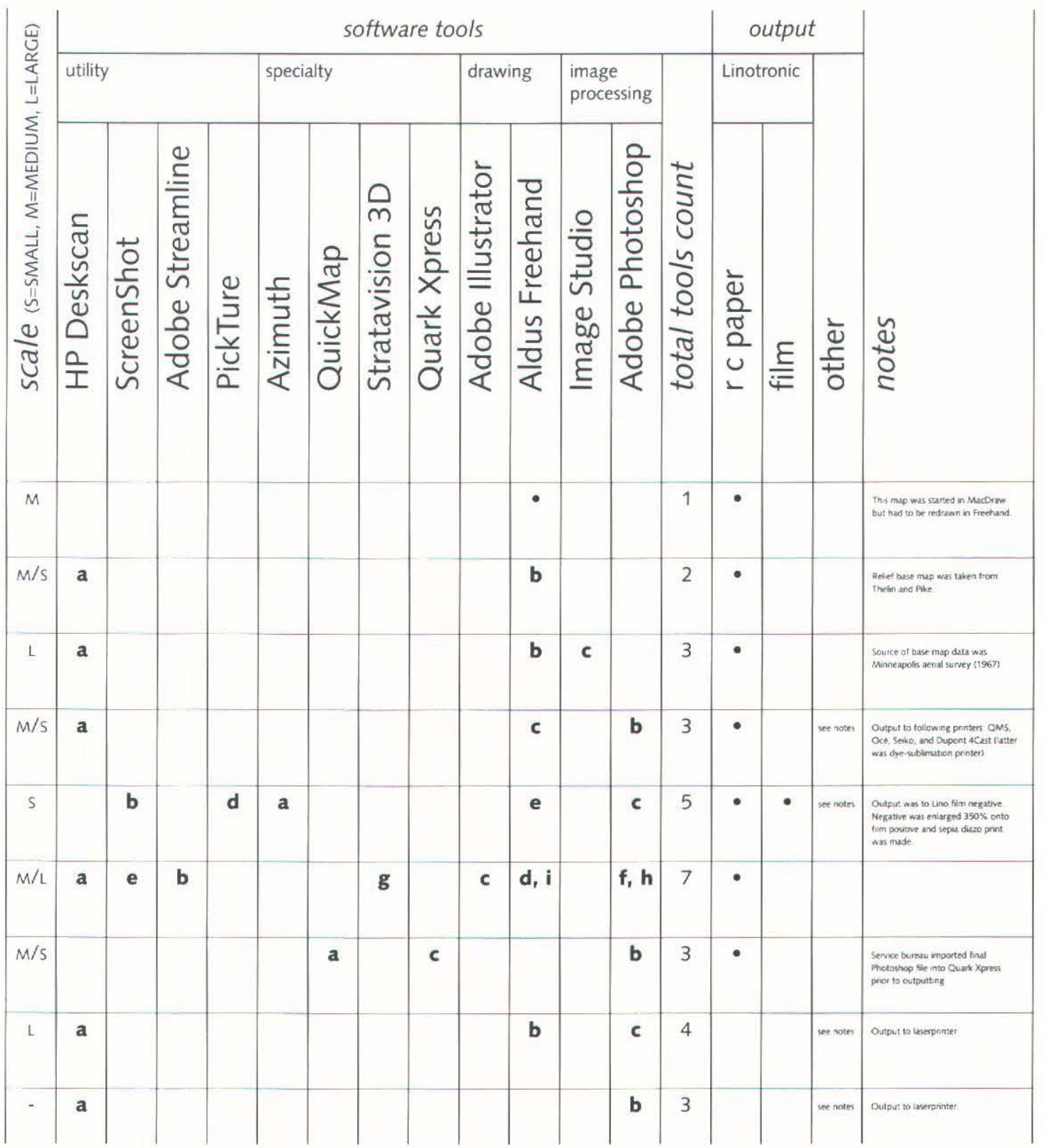


Divorce Transect: One-Tool Map This map (right) demonstrates use of the geographer's technique of transect analysis, i.e. data collection along a line that one traces across a landscape. I used the 114th meridian as my transect line and hypothesized notable differences in divorce rates in counties on opposite sides of this line because it separates a "Mormon" Utah from a more "Godless" Nevada.

Choropleth data expression was employed. Software used was Aldus Freehand.
Minneapolis Neighborhood:

Three-Tooled Map

The map at right depicts a four block neighborhood. A blueprint of streets, sidewalks, and house plans was procured from a county source, scanned, and then placed in the background layer of a Freehand document for drawing reference. An effort was made to plan the best use of gray values to portray various line and area features. ImageStudio was used to create black horizontal bands that functioned as distinctive backdrops for headline and subhead labels.
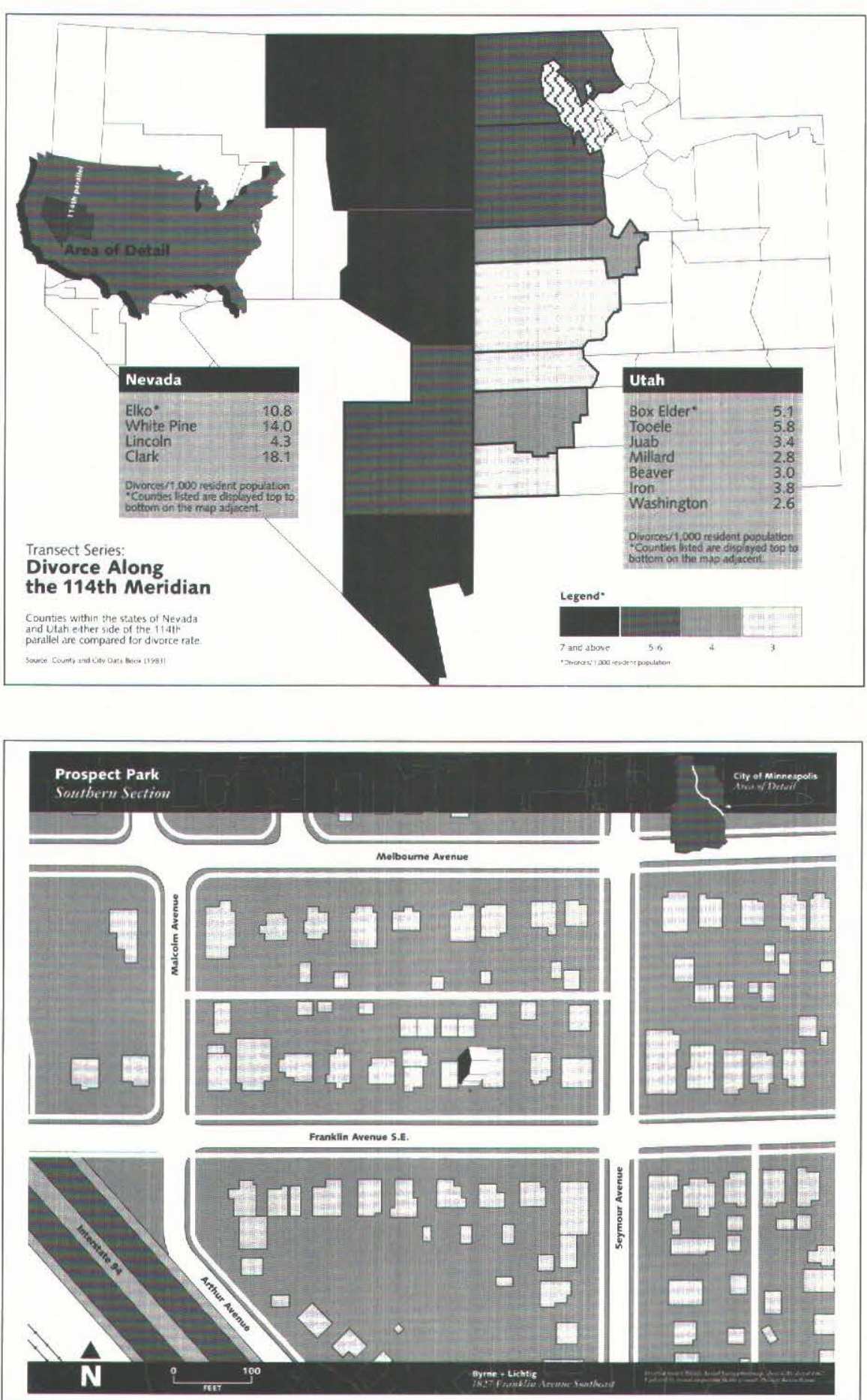

Short Printed Tutorial

A detailed log of notes on map genesis and development was made for the urban map. I created screen dumps of the various phases and wrote captions that referenced key steps. This was assembled into a narrative form within a Quark Xpress document (sequence of four pages featured to right). My goal was to transform images and notes into a brief tutorial on the specifics of large-scale urban map design.
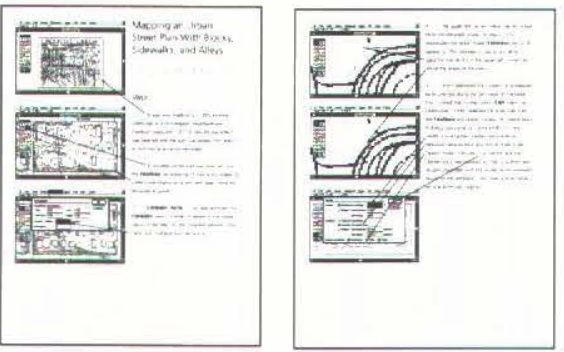

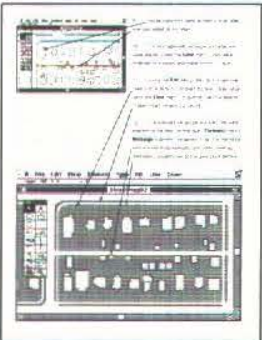




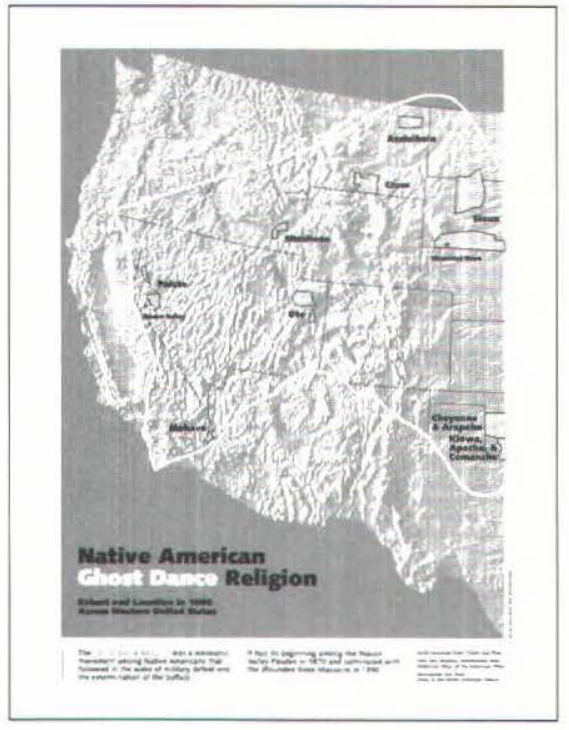

\section{Ghost Dance: Two-Tooled Map}

Content for the demonstration map to the left was taken from an atlas of the western United States (Beck and Haase 1989). The goal was to restyle an existing atlas page completely on a "Macintosh desktop" in an effort to see what substantial value-pattern enhancements could be realized. (The context for this pursuit was purely experimental and non-commercial.) The basemap featured was scanned directly from Pike and Thelin's shaded portrayal of relief that was featured in Cartographic Perspectives (Pike and Thelin 1990-91). This scan was placed in Freehand and its value was uniformly lightened. Historical atlas information on Native American ghost dances (Beck and Haase 1989) was scanned and placed in a background layer as a reference for redrawing. Line, shade, and text were added to complete the map.

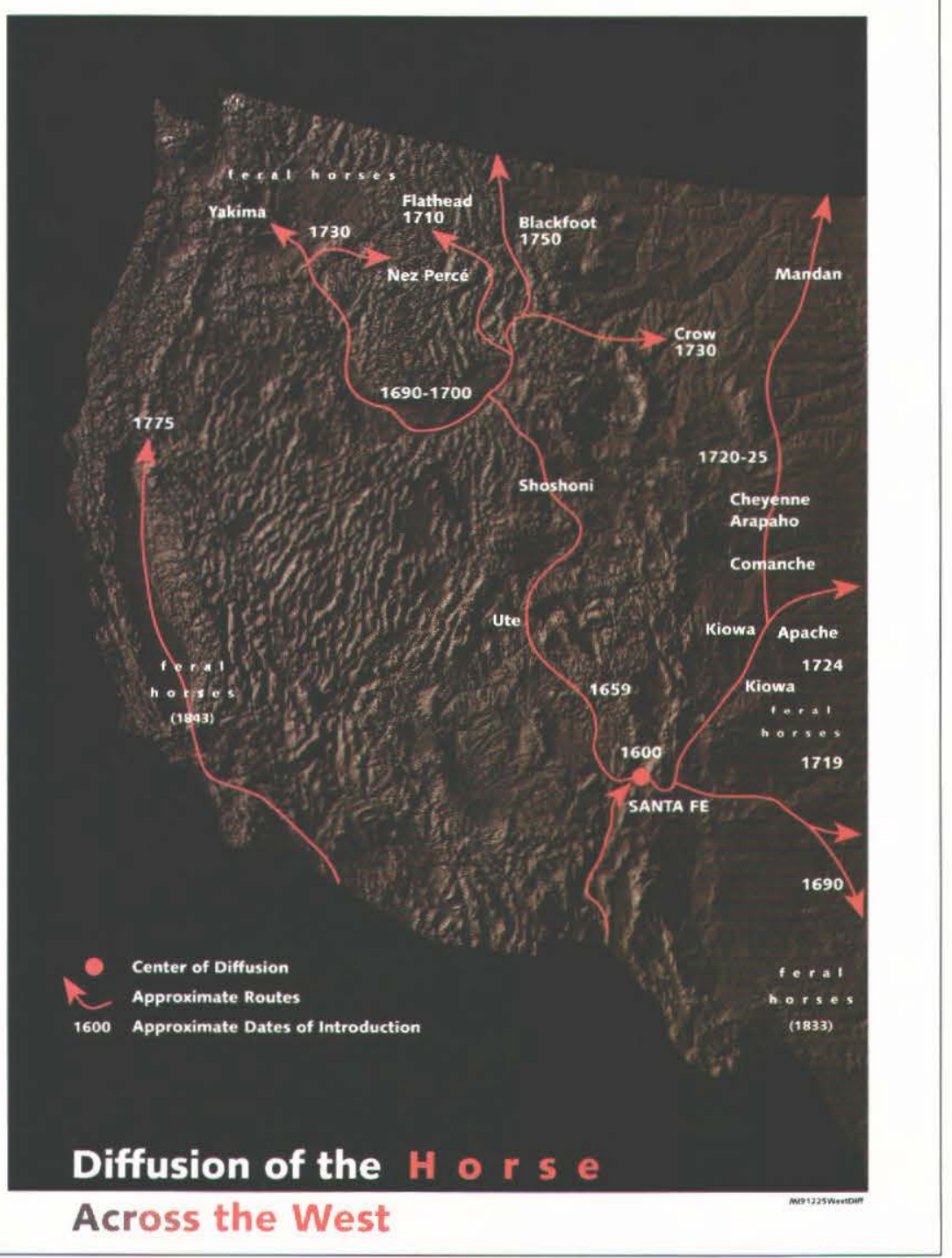

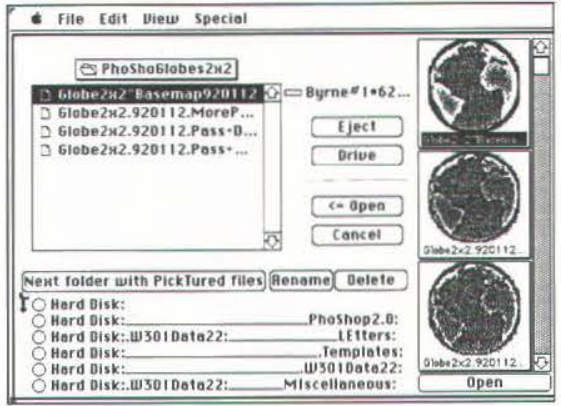

(Pickture visual file selection software tool. Refer to page 17 caption.)

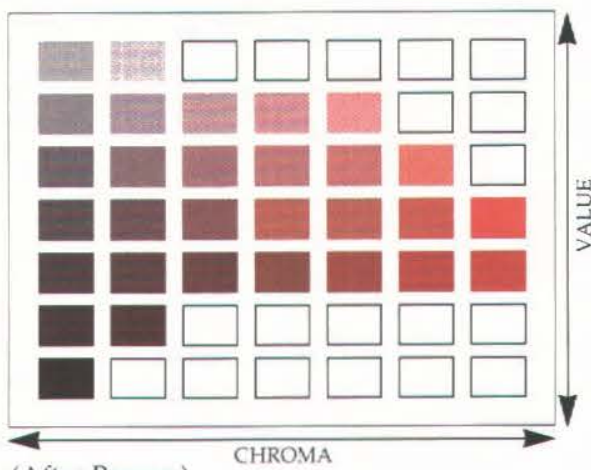

(After Brewer)

Horse Diffusion: Three Tools in Support of a Systematic Color Progression

A demonstration map (left) was another effort at redrawing from an existing atlas. The scan from the aforementioned United States shaded relief (Pike and Thelin 199091) was opened in Adobe Photoshop for coloring. An earth hue was chosen and applied across the entire map. The resulting file ( 3.5 megabytes in size) was placed in a Freehand document as an underlayer. An atlas page featuring the diffusion of horses (Beck and Haase 1989) was scanned and placed in a background layer as reference. I utilized a well-conceived color chart that featured perceptual dimensions of Munsell's color system (Brewer 1985) to help me make a modest selection from harmonic color progressions. I created a digital CMYK swatch table using red as a target hue (figure above). Several color progressions were then taken from this swatch and worked into line and text features on the map. (The map was then output to five different printers for making judgements about the appropriateness and quality of today's pre-press proofing technology.) 
Frontiers Travel: Five-Tooled Map A demonstration map was conceived that would compare travel times of the first Columbian and daGaman trips with later ocean voyages. Five tools were utilized. Azimuth software was first used to create an azimuthal projection aimed at a globe with the goal of precisely featuring Southern African and North American continents with attendant graticules (upper left figure). The screen was captured using ScreenShot and opened in Adobe Photoshop for "illustrative" image processing. Filters such as blur, diffuse, high-pass, and sharpen were employed (lower left) in pursuit of a distinctive roughness and glow that connoted "age." Dozens of Photoshop versions were created, thus demanding cataloging software; I used Pikture for the purpose of quickly comparing and organizing the retrieval of visual results (see figure on page 16), eventually leading to a final choice of a globe to serve as a basemap. This globe was exported as an EPS file and then placed into a Freehand document. There it was duplicated and line features and text were added (upper right). The file was output to an imagesetter for final review. The illustratively-processed globe with its flowlines was also incorporated into the design of a cover for hypothetical atlas pertaining to this theme (lower right, second over) using Freehand.

Farmland Relief: A Seven-Tool Traverse This map was a response to a request made by an author who is writing about a farm in the Rochester, Minnesota area. A topographic sheet was provided that showed the farm property as a penciled boundary. I made an ink tracing of the contour sheet and scanned it (top figure left). This file was opened in Adobe Streamline which was used to auto-trace the scanned lines. The Streamline file was opened and saved in Adobe Illustrator (top, second from left), then opened in Freehand for manipulation. Each contour was closed into a shape. Each shape was then assigned a gray value based on contour interval (top, third from left). The farm boundary was crisply delineated (top, far right) and a screen dump was made using ScreenShot. This was opened in Photoshop and filtered so the value ramp was smoothed. The file was then inverted (middle row left) and placed in Stratavision 3D, which has a feature that creates relief based on value (i.e. the lighter values are projected higher than darker ones, simulating dimensionality).

Viewpoints were explored (lower left) and one was saved, opened in Photoshop, lightened, saved as a TIFF file, and finally placed in a new Freehand document. Roads, creeks, buildings, and text were added to finish the map (lower right).
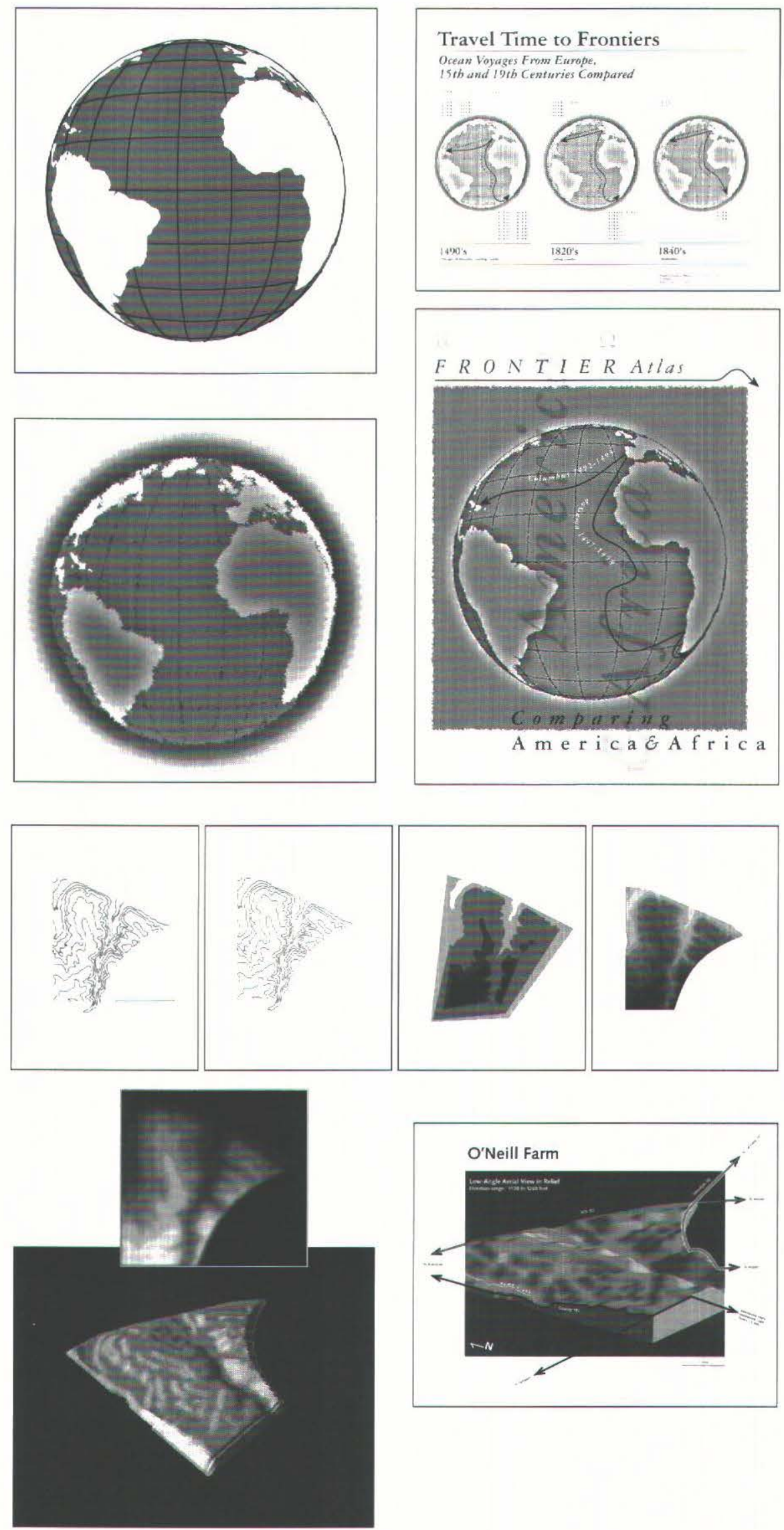


\section{U. S. Divorce Map}

- QuickMap: a table taken from census data was imported into this Hypercarddriven G.IS toel and a map depicting divorces by state was automatically range graded and drawn as choropleth. The resuit was saved in a MacPaint format (part of the map is adjacent, screenedback).

- Photoshop: the MacPaint file was opened in Photoshop and experiments were attempted to "texturize" the map, first using only the diffuse filter (center figure) and later using blur, noise, and diffuse in combination, the latter serving to create something of a "watercolor" feeling (far right).

-Quark Xpress: the service bureau placed the final Photoshop file into Quark before outputting it to an imagesetter.
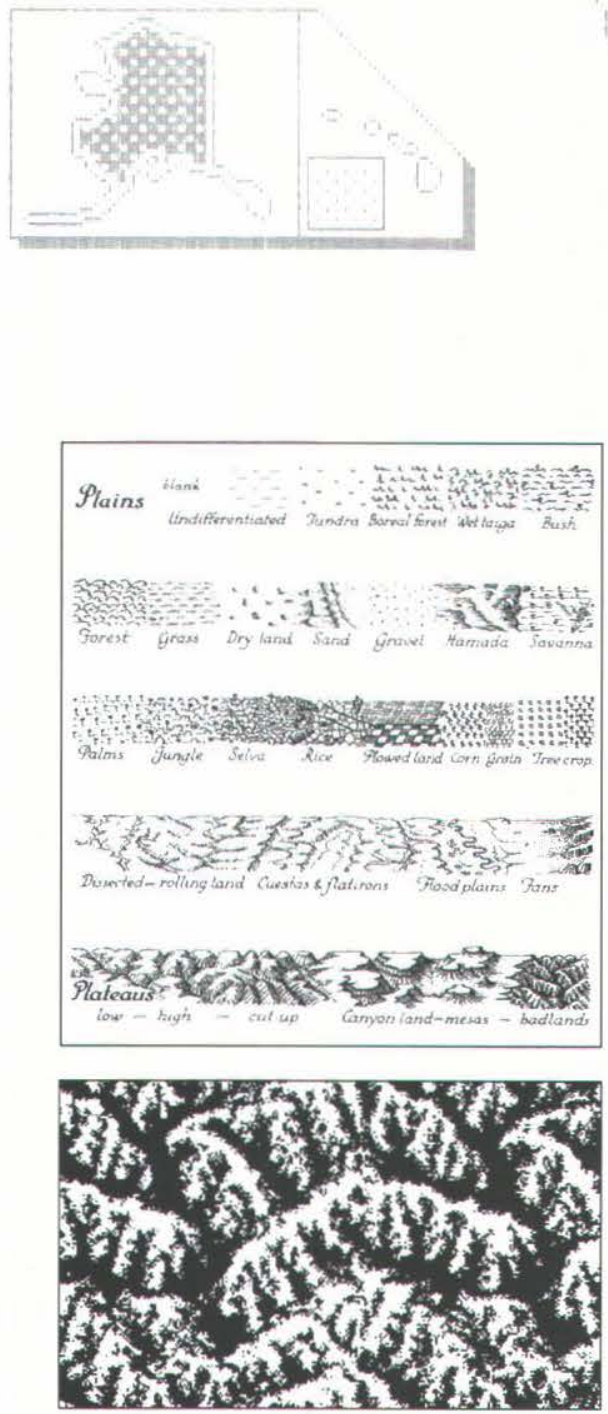

"Digital Pattern Painting" Derived from Erwin Raisz's Classic Work

Erwin Raisz was a cartographic champion of a special kind of map symbolization featured in many of the landform maps and atlases he designed. His textbook on cartography contained a chapter displaying a variety of physiographic symbols applied (as patterns) to his landform maps. In support of his expressive patterns Raisz stated (Raisz 1962):

[Though] the idea of applying...obliquely viewed landform drawings to vertically viewed maps... is bad geometry, it turn|s] out to be good psychology, as such drawings show the land more or less as we are accustomed to seeing it.

I endeavored to resurrect some Raisz landform patterns for a little digital experimentation (to serve educational goals).

- Scanning: I scanned a page of patterns from Raisz's textbook (Raisz 1962, 80) using Deskscan (figure top left)

-Photoshop: I launched Photoshop and opened the scanned patterns into it. I experimented to determine if and how some of Raisz's patterns might fare when brushed across the page. "Badlands" (far left) and "plowed land" (immediately below) are shown. In advance of pattern painting I tried a suite of Photoshop filters to give a few pattern swatches some illustrative character (also below). Results evoke some ambivalence in my mind. Basically, one can get this kind of pursuit to work, but at a cost (in the end) of a visually-stiff appearance. Regarding the latter, perhaps a randomness algorithm (yet to be written) might be a desirable addition to the filtering task.

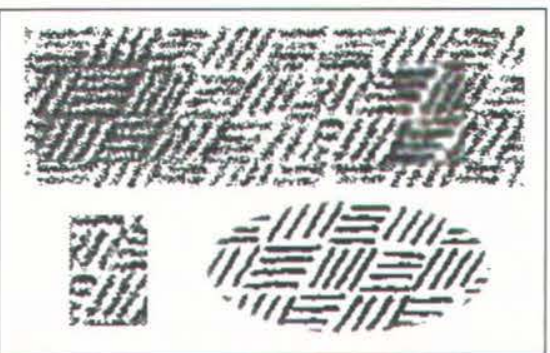


Has certain software that cartographers find most productive chained us to a limited set of connotative expressions? I recall Barbara B. Petchenik's seminal article from the early 1970's in which she articulated the need for "a systematic...attempt...in cartographic design to specify design goals for...maps...by means of several levels of verbal descriptors." (Petchenik 1974). Here are but a few the semantic descriptors she listed...

texture...hard-soft, coarse-fine

light... bright-subdued, light-dark, high contrast-low contrast, clear-blurred, transparent-opaque/dense

emotions...jouful-somber, modern-traditional, crude-elegant

In many ways her list is quite timeless. Using it properly still can help one mix-and-match the right connotative feelings for a map to be successful. Image processing tools designers use today actually echo quite a few words from Petchenik's list-i.e. they are found as menu selections or dia$\log$ box buttons in Adobe Photoshop, Fractal Design Sketcher, and other art-based image-processing software applications: bright(ness), light(en), dark(en), contrast, blur, and opacity (refer to figures right). The presence of words like these in menus seems to suggest that by arbitrarily selecting software today we could in fact be led down predetermined pathways of forms and feelings, especially if we care little for the connotative goals that grow out of the map content itself. In my own mind assets and liabilities are starting to emerge more clearly from that creative haze over our digital desktops. Liabilities: given the ever-growing menus of our software tools, we may be in some danger of being too easily and too often "charmed." Assets: nevertheless, given the complexity achievable by the combination of such tools, we regularly uncover new choices that can yield quite surprising opportunities. What remains is a clear need for a verbal audit of map message goals (to be conducted jointly by map designer and client) that can then prime a "techno-inspired" pursuit of agreed-upon feelings. At that point connotations should be fully subject to the charm and surprise of today's most productive imaging tools. For now this may still remain something of an odyssey but, as the late Dr. Petchenik once suggested, it all might serve us better if guided by "a process...more comprehensive, coherent, and...explicit than it is now."

Beck, Warren A., and Ynez D. Haase. 1989. Historical Atlas of the American West. Norman, OK: University of Oklahoma Press.

Brewer, Cynthia. 1985. Process Color Charts Based on the Munsell Color System. Photocopy accompanied by a set of offset-printed plates circulated to cartographic educators.

Petchenik, Barbara B. 1974. A verbal approach to characterizing the look of maps. American Cartographer 1: 63-71.

Pike, Richard J., and Gail P. Thelin. 1990-91. Mapping the nation's physiography by computer. Cartographic Perspectives 8: 15-23.

Raisz, Erwin. 1962. Principles of Cartography. New York: McGraw-Hill.

Thrall, Grant I. 1992. Editing video images of GIS maps: taking the "integrated" out of GIS software. Geo Info Systems 2 (7): 76-79.

\section{CONNOTATIVE CHARM: CONCLUDING THOUGHTS ON A DOUBLE-EDGE TO TOOLS}
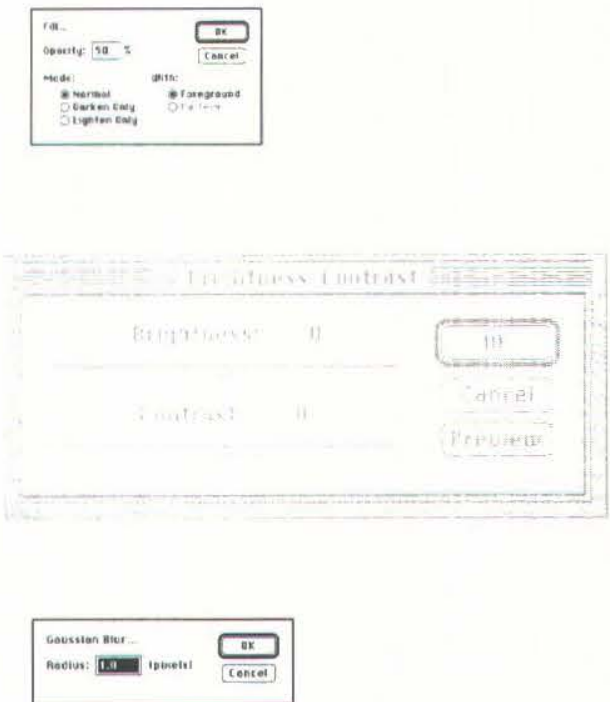

REFERENCES 
The author 1) credits the University of Oklahoma Press and McGraw-Hill for atlas and symbol pages used as a central reference in several demonstration maps herein, and 2) acknowledges that copyright of such source material is held by them. Due to the wholly educational nature of this endeavor, the fair use clause of copyright law is deemed fully applicable. All other maps @ 1993 Kevin Byrne.

Azimuth is a trademark of Graphsoft. DOS and Windows are trademarks of Microsoft. Freehand is a trademark of Aldus. Illustrator, PhotoShop, and Streamline are trademarks of Adobe. MacDraw is a trademark of Claris. Macintosh is a trademark of Apple. MGE is a trademark of Intergraph. PickTure is a trademark of Right Answers. Quark Xpress is a trademark of Quark. Quickmap is a trademark of MicroMaps Software. Sketcher is a trademark of Fractal Design. StrataVision 3D is a trademark of Strata. ScreenShot 1.0 is FKEY shareware. Other references to trademarked software and manufacturers may have been made in this article. Such registration may be taken as read. Software versions used were firstrelease except for Deskscan, Freehand, Illustrator, MacDraw, PhotoShop, Streamline, Quark Xpress, and StrataVision 3D (wherein advanced versions were utilized).

The author thanks Paul Stayert for editorial comments.

RESUMEN La edición de mapas y de plataformas computarizadas de desktop es una odisea que obliga al diseñador a trazar campos minados de flujos de trabajo no integrados. Este artículo detalla el flujo de trabajo de 9 mapas producidos con software para computadoras de escritorio. Cada flujo de trabajo se ejecuta a través de una hilera y cada hilera hace referencia a una matríz de encabezamiento que es un resultado tanginble de la implementación cartográfica de libre diseño de desktop, usando el procesador de imágenes y otros programas de software. La necesidad de articular las metas para guiar el poder y el encanto del software debe discutirse. 